\title{
INFLUENCE OF STRUCTURAL AND FRAGILITY MODELLING DECISIONS IN THE LOSS ASSESSMENT OF RC FRAME BUILDINGS
}

\author{
David P. Welch ${ }^{1}$, Timothy J. Sullivan ${ }^{2}$ \\ ${ }^{1}$ ROSE Programme, UME School, IUSS Pavia \\ 1 Via Ferrata, Pavia, PV, Italy, 27100 \\ david.welch@umeschool.it \\ ${ }^{2}$ Department of Civil Engineering \& Architecture, University of Pavia \\ 1 Via Ferrata, Pavia, PV, Italy, 27100 \\ timothy.sullivan@unipv.it
}

Keywords: Building Specific Assessment, Expected Annual Loss, RC Frames

\begin{abstract}
Much advancement in structural modelling, seismic hazard analysis, and component fragility estimation techniques has been made in recent years; all of which have contributed to the feasibility of conducting building-specific loss estimates. This paper investigates the impact that certain modelling decisions can have on the outcome of loss estimates using a probabilistic performance-based earthquake engineering approach. These variations include assumptions on initial member stiffness, treatment of elastic damping, and the hysteretic properties of RC members. Further, the effect of the choice of component fragilities and decision variable formulation is investigated by implementing two loss models adopted in previous research efforts. Analyses are conducted for a benchmark four-story RC frame building that was previously assessed to allow a comparison with previous results and thereby confirm the reliability of the implemented methodology.

The use of the expected annual loss to convey performance is shown to be the most sensitive to modelling decisions given the high contribution of lower intensity seismic excitations and initial accumulation of damage. Scenario-based loss assessments show a more consistent result between model variations that adopted the same loss model formulation. Finally, the two different loss models utilized in this study are shown to provide the largest source of deviation in loss estimates. This highlights the need for additional research, to more accurately define loss models for seismic assessment purposes.
\end{abstract}




\section{INTRODUCTION}

Modern seismic code provisions have presented, as a majority, their effectiveness to prevent collapse and loss of life following recent earthquakes. Conversely, many of these events have revealed a common and concerning situation of severe component damage and even precollapse replacement decisions that have led to an increasing focus on the development of Performance-Based Earthquake Engineering (PBEE). Much advancement in structural modelling, seismic hazard analysis, and component fragility estimation techniques has been made in recent years; all of which have contributed to the feasibility of conducting building-specific loss estimates. Most notably, the development of the Pacific Earthquake Engineering Research (PEER) center's PBEE methodology represents the pioneering compilation of these advances within a four stage approach which considers initial site through the expected repair costs and post-event conditions.

The current research is aimed to investigate how building-specific loss estimates are affected by variations in structural modelling decisions as well as differences within the loss model approach adopted. The investigation is carried out through the analysis of a four-storey reinforced concrete (RC) case study building that was previously assessed using two different loss model approaches which allows for an additional comparison to be made with respect to the reliability (repeatability) of the PEER PBEE methodology. Variations of structural modelling decisions addressed herein reflect some of the decisions that are typically left to the intuition of the analyst, including: initial member stiffness, treatment of elastic damping, and post-yield behaviour of structural elements. Notably, the current study aims to simply address the possible variations in loss estimates without any attempt to quantify the actual uncertainty associated with these variations; producing a platform to discuss the implications of structural modelling decisions combined with different adopted loss models.

The loss metrics or decision variables considered within the study consider only the losses associated with repairing damage and the costs associated with the total collapse of the building, termed here as direct losses. The additional decision variables that can be involved are numerous [4], yet the current study focuses solely on this type of loss.

\section{OVERVIEW OF CASE STUDY BUILDING}

\subsection{Building details}

The case study building is a four-storey RC frame building realized with a space frame design featuring special moment-resisting frames (SMRFs) on each column line. The building is assumed to be located within the Los Angeles basin in California on a site with deep soil conditions (NEHRP class D) possessing an average shear wave velocity of $285 \mathrm{~m} / \mathrm{s}$ [1]. A probabilistic seismic hazard assessment (PSHA) for the site was conducted by [2]. The building is regular in plan and elevation with four $30 \mathrm{ft}(9.1 \mathrm{~m})$ and six $30 \mathrm{ft}(9.1 \mathrm{~m})$ bays in the North-South and East-West directions respectively. The storey heights of the building are 15 $\mathrm{ft}(4.6 \mathrm{~m})$ and $13 \mathrm{ft}(4.0 \mathrm{~m})$ for the bottom storey and the upper stories respectively. The design of the building was taken from [1] that produced a simplified three-bay representation of the building as shown in Figure 1.

The reinforcement scheduling conforms to the 2003 International Building Code. Member dimensioning and detailing was controlled by joint shear requirements and columns are designed to Strong-Column Weak-Beam (SCWB) provisions. The target SCWB factor was 1.2, but it is noted that the resulting SCWB factors from assessment strengths are on the order of 1.3 for the first three stories and less than unity $(<1.0)$ for the roof level. More in depth information about the design of the frame building can be found within [1]. 


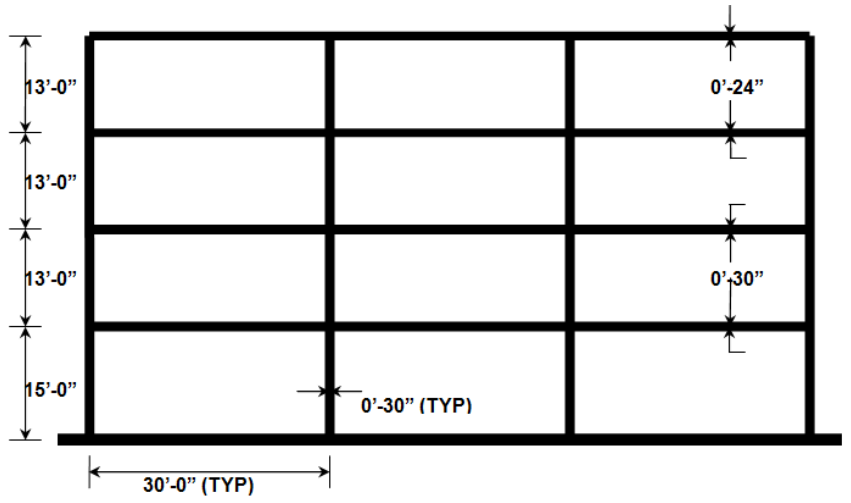

Figure 1: Elevation view of case study building (reproduced from [14])

\subsection{Building occupancy and contents}

The four storey case study building is a standard building with office occupancy. The building possesses lightweight gypsum drywall partitions with $35 / 8$ inch $(92 \mathrm{~mm}$ ) deep studs with $5 / 8$ inch $(16 \mathrm{~mm})$ thick wallboards, and are assumed to have fully attached top plate connections as opposed to free "slip-track" connections. The exterior of the building is comprised of single glazing assemblies with $5 \mathrm{ft} \times 6 \mathrm{ft}(1.5 \mathrm{~m} \times 1.8 \mathrm{~m})$ panes within an aluminium frame. The ceiling system utilizes $2 \mathrm{ft} \times 4 \mathrm{ft}(0.6 \mathrm{~m} \times 1.2 \mathrm{~m})$ lightweight ceiling tiles set in aluminium framing suspended by splay wires with vertical compression struts. The mechanical items, such as electrical, HVAC and fire suppression (sprinklers), are assumed to be properly anchored according to modern seismic design requirements mandated by the component's respective industry standard [3]. The general architectural layout within the building has more open space at the ground floor while a more heavily partitioned layout is assumed for the remaining levels. For more detailed information on the architectural layout, contents, and takeoff quantities the reader is referred to [3].

\section{IMPLEMENTED LOSS ANALYSIS PROCEDURES}

\subsection{Overview of the probabilistic PBEE framework}

The assessment of the case study building is carried out by following the analysis procedure outlined within the Pacific Earthquake Engineering Research (PEER) Center's Performance-Based Earthquake Engineering (PBEE) framework as described within [4]. The framework consists of four analysis stages: site hazard definition, structural analysis, damage calculation, and decision variable calculation as shown in Figure 4. The framework begins with the structure definition, $D$, including both structural and non-structural configurations and the geotechnical properties of the proposed site. For a given site, the hazard analysis stage is carried out typically in the form of a Probabilistic Seismic Hazard Assessment (PSHA) which provides the mean annual frequency, $\lambda$, of an intensity measure, IM, of interest as well as uniform hazard spectra and disaggregation information in order to guide accelerogram selection for the structural analysis stage. Notably, the PSHA conducted by [2] provides mean uniform hazard spectra at eight intensities and a complete hazard curve at periods of $0.2,1.0$, and 2.0 seconds.

The structural analysis stage requires that a structural model is created in order to perform non-linear time history simulations of the site and structure from which the probability density of engineering demand parameters (EDP's) conditioned on a given intensity measure, $p[E D P \mid I M]$, can be evaluated. Using the EDP distributions, the likely damage of the structural and non-structural contents can be evaluated usually through the assignment of log- 
normally distributed fragility functions that represent the probability of a given damage measure, DM, of a component conditioned on a given EDP such as peak inter-storey drift. Using the results from damage analysis the repair quantities for the building components are estimated by repair cost functions from which a decision variable, DV, can be quantified and the overall performance of a given site and design combination, D, can be assessed. Notably, the expected total repair cost of a given structure conditioned on IM is a common DV to be quantified but other DV's may address the probability of collapse and the expected external impact (e.g. downtime or business disruption) from a given level of seismic intensity [4].

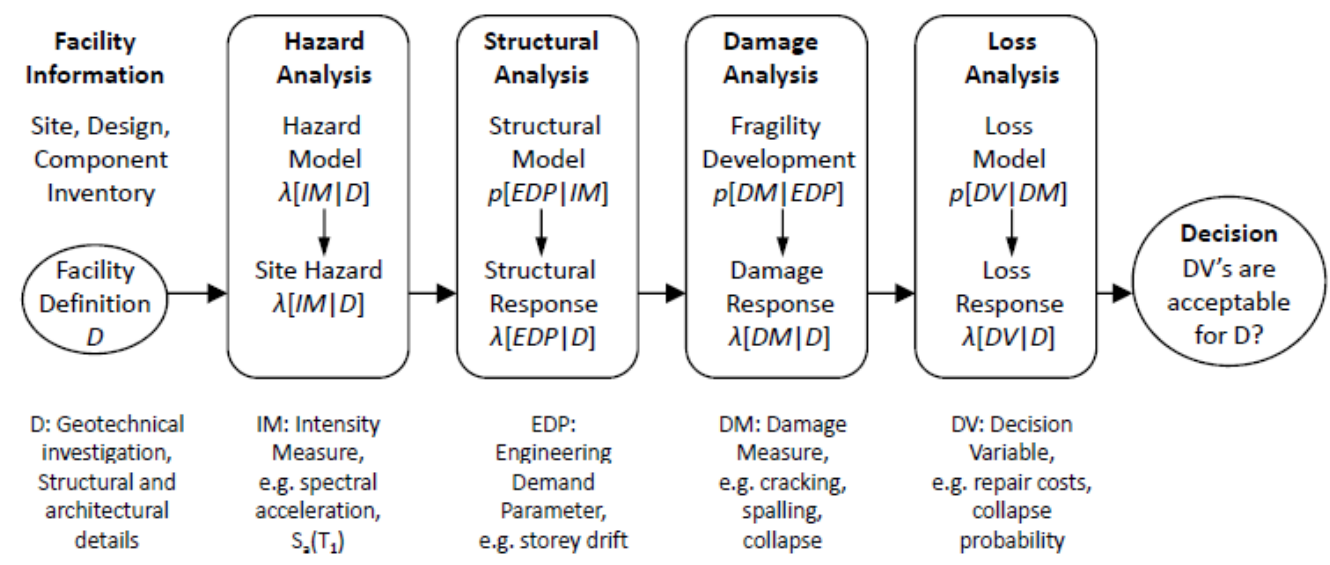

Figure 4: Overview of the PEER PBEE framework (after [4]).

The mathematical representation of the methodology is illustrated in Eq. (1) where the annual occurrence frequency of a given DV, say repair cost, is represented by $\lambda[D V \mid D]$ and is calculated through the evaluation of the triple integral shown, where all the terms are conditioned on the particular structure D.

$$
\lambda[D V \mid D]=\iiint p[D V \mid D M] p[D M \mid E D P] p[E D P \mid I M] \lambda[I M] d I M d E D P d D M
$$

As an objective of this paper is to investigate the sensitivity of decision variables to a given loss model, two different loss models are considered in this work.

\subsection{Component-based loss model}

The first of the two loss models considered is a component-based (CB) loss model previously developed and implemented within [3]. The term component-based is used as repair costs of the structure are estimated by considering individual damageable assemblies by assigning independent fragility and repair cost functions for the last two stages of the PEER PBEE framework described in section 3.1. The damageable assemblies considered in this work (after [3]) are beams, columns, partition walls, interior paint, exterior glazing, acoustical ceilings, fire suppression systems (sprinklers), and conveying systems (elevators).

Two pertinent aspects of the CB loss model adopted herein is that the structural damage is quantified using a curvature based damage index that requires the estimation of the recoverable curvature of members and the total replacement cost of the structure is calculated based on the replacement cost of every component assigned a damage and repair fragility. Notably the results of [3] show that the replacement cost of the building is taken as $\$ 9,000,000$ expressed in 2007 USD. This value will be used to express the loss estimates in terms of a mean damage factor (MDF) which represents the percentage of replacement cost of the structure. 


\subsection{Storey-based loss model}

The second of the two loss models considered is a storey-based (SB) loss model developed within [5]. As the name suggests, the SB loss model assumes the combined fragilities of a single storey content through the development of engineering parameter to decision variable (EDP-DV) functions that allow for the direct estimation of direct losses from structural analysis results. The EDP-DV functions are developed based on expected occupancy, structural system, and building height [5]. The EDP-DV functions utilize only inter-storey drift ratio (IDR) and peak diaphragm acceleration (PDA) as EDP's and discretize the damageable assemblies into three performance groups: structural, non-structural drift sensitive, and nonstructural acceleration sensitive. The set of EDP-DV functions implemented for the current study were constructed to represent a low-rise ( $\leq 5$ stories), ductile, reinforced concrete space frame with office occupancy (refer [5]). The functions relate expected contents based on the first, typical, and roof levels where an example of the EDP-DV functions assumed for the first floor are shown in Figure 5.
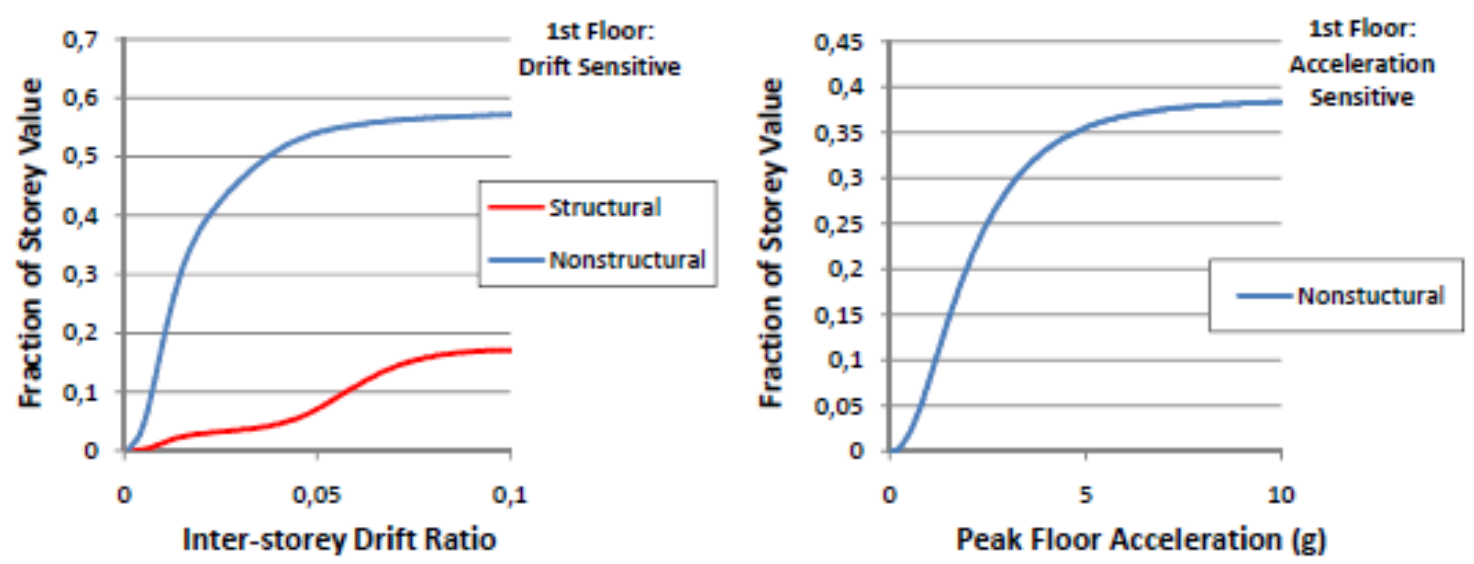

Figure 5: EDP-DV functions assumed for the first floor of the case study building (after [5]).

For the current study, it is assumed that the stories have an equal value of $25 \%$ of the replacement cost. The replacement cost of the case study building was calculated by [5] to be $\$ 12,500,000$ in USD from construction estimating references however the loss models are best compared by reporting losses expressed in MDF.

\subsection{Considered loss metrics}

In order to gauge the seismic performance of the case study building a series of loss metrics are considered: expected loss for a design basis earthquake (DBE) scenario, and expected loss for a maximum credible earthquake (MCE) scenario, expected annual loss, and net present value of loss over 50 years.

The first two loss metrics are termed scenario-based assessments as the resulting estimate corresponds to a single event occurring based on return period, magnitude-distance couple, or other measure [7]. In much of the Western United States the DBE and MCE events correspond to a $10 \%$ and $2 \%$ probability of exceedence in 50 years respectively.

Expected annual loss (EAL) represents a time-based assessment of the likely losses a building can be expected to endure in any given year from a probabilistic standpoint [7]. The EAL considers the entire range of seismic intensities expected at a site in combination with the corresponding mean annual frequency and expected losses at each intensity. 
The use of EAL as a loss metric is a valuable parameter as it allows for an estimate of what annual insurance premiums would be reasonable for a given building [7,8]. Additionally, it can be useful in order to convey loss estimates in terms of the net present value over the lifetime of the building, taken here as 50 years. For example, the net present value $\left(\mathrm{NPV}_{50}\right)$ of losses may assist in a seismic retrofitting decision where $\mathrm{NPV}_{50}$ would represent the amount a risk-neutral owner would be willing to invest [8]. The $\mathrm{NPV}_{50}$ is calculated from the EAL using an assumed discount rate, $\mathrm{r}_{\text {discount }}$, of $3 \%$ as shown in Eq. (2).

$$
N P V_{50}=\sum_{t=1}^{50} \frac{E A L}{\left(1+r_{\text {discount }}\right)^{t}}
$$

Although the choice of discount rate can significantly change NPV estimates [8], the main purpose for addressing NPV of loss is to illustrate EAL estimates at a similar order of magnitude as the two aforementioned scenario-based assessments.

\section{STRUCTURAL ANALYSIS MODEL}

The structural model utilized for the current study is developed in the finite element program RUAUMOKO [9]. The building is modeled as a three bay representation as shown in Figure 1. The base columns are assumed fixed at the base and the effects of soil structure interaction are neglected based on the previous findings of [10] using similar site and structure characteristics. The lateral mass is modeled assuming $1.34 \mathrm{kip}-\mathrm{s}^{2} / \mathrm{in}(235 \mathrm{~T})$ at each floor level with tributary masses lumped at the beam-column nodes. Second order effects (P-Delta) are accounted for during analysis using the "P-Delta" option in RUAUMOKO (refer [9]). During non-linear time history (NLTH) analyses Newmark constant average acceleration integration is implemented with an analysis time step of 0.001 or 0.002 seconds depending on the accelerogram. The treatment of structural collapse assumes a collapse fragility reported in [1] as collapse probabilities are not expected to significantly affect loss results for the modern 2003 IBC conforming design (refer $[1,6]$ for details).

\subsection{Modelling structural elements}

The columns of the case study building are modelled as concrete beam-column frame elements while the beams are modelled as two point Giberson beam elements within the program Ruaumoko [9]. Both types of structural members assume lumped plasticity at the member ends with an elastic element spanning between plastic hinges. As a main objective of the current study is to compare the results of repeating the probabilistic loss assessment procedure to previous studies, the structural elements should ideally be modelled (reasonably) in the same manner as the benchmark study. As such, much information about the structural elements was taken from [1] in order to remain consistent.

Using material properties defined in [1], moment-curvature analyses of the RC beam and column sections were conducted using the program CUMBIA [11]. The resulting beamcolumn section properties were found to be in good agreement with those reported in [1] with nominal moment strengths (the definition of nominal moment strength and yield curvature is illustrated in Figure 6) and first yield moment strengths that encompassed the expected yield moment reported in [1]. Similarly, the ultimate moment strength, $M_{u}$, values had a maximum deviation of $+12 \%$ and were within $2 \%$ of previously reported values on average. Finally, the program CUMBIA returned estimates of rotational capacity based on ultimate failure (reinforcement rupture or core crushing) and the onset of reinforcement buckling that bounded the reported rotational capacities within [1]. Therefore the assumption was made to assume that the previously reported rotational capacities would be adopted for the current study. The 
beam-column elements are calibrated for monotonic loading according to a tri-linear backbone curve based on the findings of [1] in terms of peak rotational capacity and the post peak failure slope while the yield moment was taken as the nominal moment strength and the peak moment was taken as the lesser of the $1.2 M_{n}, M_{u}$, and the moment corresponding to reinforcement buckling. Beam elements assume the average rotational capacity of 0.06 radians and assume yield and peak moment strengths of $M_{y, \exp }$ and $1.2 M_{y, \exp }$ as provided in [1]. An example of the backbone curve is illustrated for a first storey interior column in Figure 6 noting that the calibration was performed before the consideration of $2^{\text {nd }}$ order effects as per recommendations in [1].
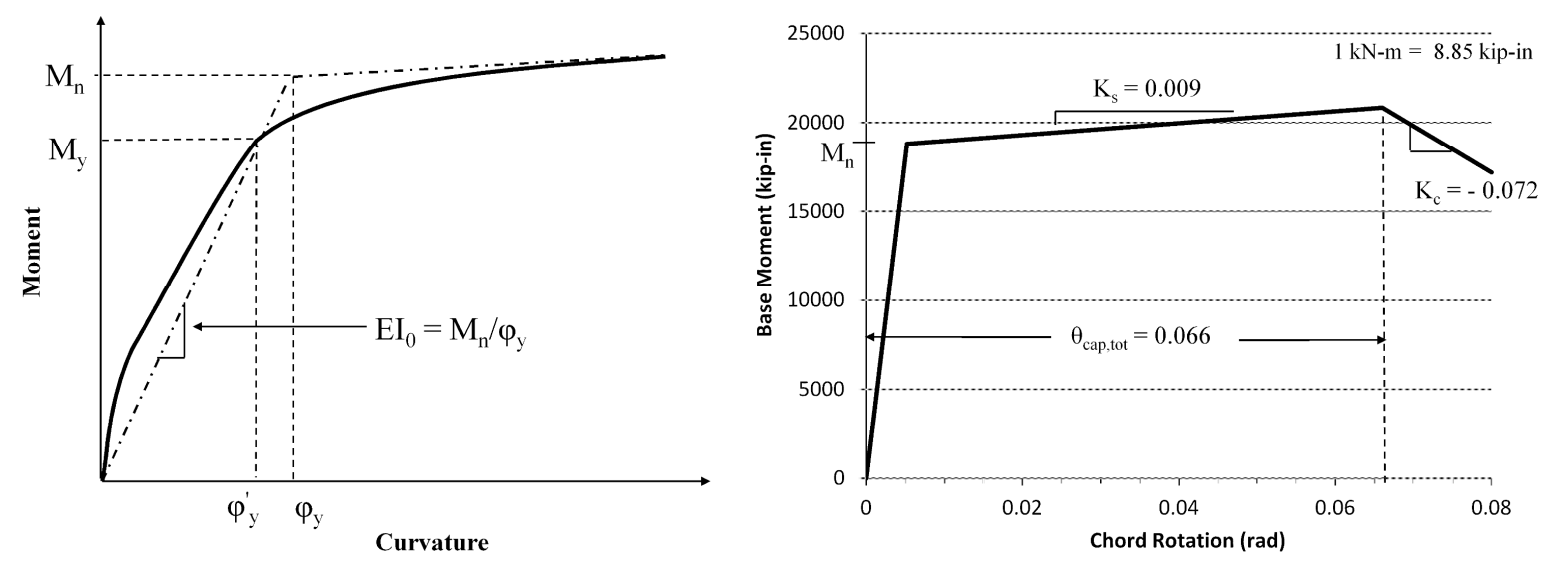

Figure 6: Nominal flexural strength and yield curvature (left), Illustration of monotonic calibration (right).

The hysteretic properties of the structural members assume a modified Takeda hysteresis as shown in Figure 7 which illustrates that in addition to the initial stiffness, $k_{0}$, and postyielding stiffness factor, $r$, parameters must be defined to determine the rate, $\alpha$, at which the displacement ductility dependent unloading stiffness decreases and the reloading stiffness factor, $\beta$, that relates the point on the backbone curve a current excursion will intercept with respect to the previous excursion. The selection of input parameters is based on assuming "Takeda Fat" (TF) hysteresis for beam members and "Takeda Thin" (TT) hysteresis for beamcolumns. Typically, TT hysteresis assumes $\alpha=0.5$ and $\beta=0$ to represent the energy dissipation expected for members with high axial load (e.g. - columns) while using a TF hysteresis with $\alpha=0.3$ and $\beta=0.6$ is representative of modern code conforming $\mathrm{RC}$ beam members [12]. These parameters are adopted for the members within the four storey space frame building.

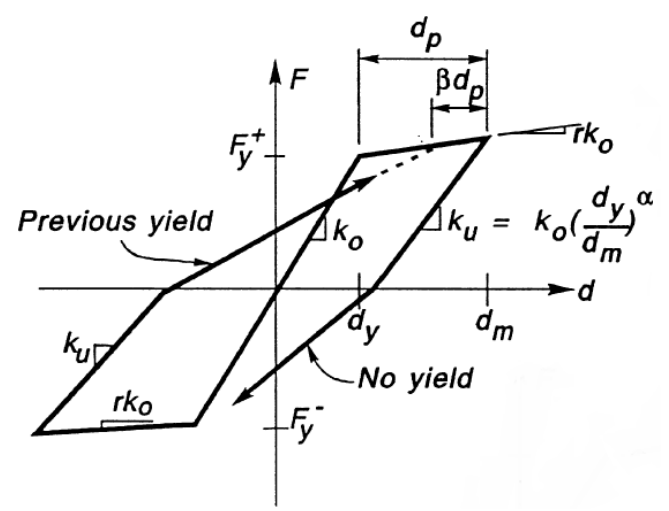

Figure 7: Modified Takeda hysteresis model (after [9]) 


\subsection{Strength degradation and post-yield stiffness of structural members}

The current study considers two general assumptions on the modelling of strength degradation of structural elements. The first considers only in-cycle degradation using the maximum ductility of the member to reduce the strength according to the monotonic backbone curve. This calibration produced a post-yielding stiffness equal to $1 \%$ of initial on average. Since the recommendations of [1] suggest that the post yielding stiffness should be $4 \%$, a second hysteretic model allowed the member to be loaded along the $4 \%$ post-yield slope until reaching $1.2 M_{n}$ and $1.2 M_{y, \text { exp }}$ for columns and beams respectively and then including both ductility dependent in-cycle and cycle-based cycle-to-cycle degradation such that the peak response would be below calibrated monotonic curve. Examples of the two simplified hysteretic models are shown in Figure 8.
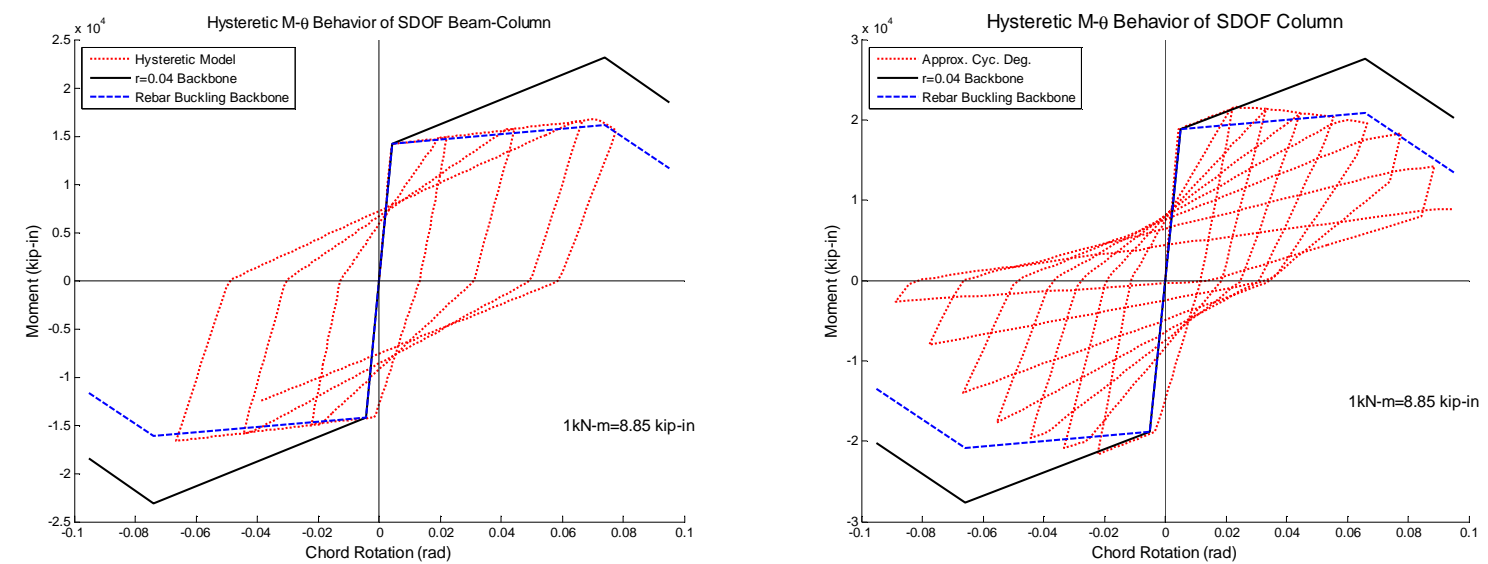

Figure 8: Ductility-based strength degradation (left), Cyclic and ductility-based strength degradation (right).

Referring to Figure 8, the black lines represent the suggested monotonic backbone by [1] and the dashed blue lines represent the reduced monotonic curve by considering the reduced peak moment in the case of reinforcement buckling. The difference in the two curves shows that although simplified strength degradation is implemented, the general response is not reproducing a calibration based on purely monotonic considerations and is assumed as a reasonable approximation in lieu of an experimental calibration study.

\subsection{Initial member stiffness}

The initial stiffness of beam-column members was varied between taking the effective stiffness corresponding to the nominal moment strength and using a relation from [1] that is based on approximating the initial stiffness as the secant stiffness through $40 \%$ of the expected yield moment, $M_{y, \text { exp }}$. The stiffness corresponding to nominal moment strength is shown by Eq. (3) based on recommendations of [12]:

$$
E I_{e f f}=\frac{M_{n}}{\phi_{y}}
$$

where all parameters have been previously defined (refer Figure 6). For brevity, the relation proposed within [1] for the secant stiffness to $40 \%$ of the yield moment resulted in the lower bound value of $35 \%$ of the gross member stiffness $\left(0.35 \mathrm{EI}_{\text {gross }}\right)$ for all beam-columns. As the relation using secant stiffness through a fraction of the yield force was shown to replicate fibre element models (distributed plasticity) with the tensile strength of the concrete modelled 
this initial stiffness comparison represents the case of a new construction situation and the case of a modern, "undamaged", building that may have been subjected to a previous lateral loading (seismic or wind). Notably, the change in assumed initial stiffness returned the same nominal first mode period of $0.8 \mathrm{~s}(0.01 \mathrm{~s}$ tolerance) which suggests that very little difference will be witnessed in the loss estimates. However, as the relation of Eq. (3) gives values that range from $42 \%$ to $25 \%$ of the gross stiffness the difference in dynamic behavior cannot be expected to be negligible. Further, the difference in the initial stiffness of individual members will produce variations in the assumed recoverable curvature (for the $\mathrm{CB}$ model) as the unloading stiffness of each member is related to the assumed initial stiffness as shown in Figure 7. The effective stiffness of beam elements assumes the values reported in [1].

\subsection{Elastic damping}

The current study will consider two values of initial stiffness proportional Rayleigh damping (ISRD). A value of $6.5 \%$ of critical has been implemented in the works of researchers that have assessed the current case-study building [1,10]. Conversely, the typical value assumed for reinforced concrete buildings can safely be set to $5.0 \%$ initial stiffness damping. These two values are implemented into the loss assessment models in order to display a single comparison of one analyst's opinion versus another with respect to the treatment of elastic damping. Additionally, a brief investigation into the impact of assigning tangent stiffness proportional Rayleigh damping (TSRD) and the effect of beam-column joint stiffness is addressed within [6] yet these findings are omitted from the current discussion.

\section{RECORD SELECTION FOR NON-LINEAR TIME HISTORY ANALYSIS}

The selection of accelerograms for non-linear time history (NLTH) analysis was carried out following the disaggregation of the site hazard from PSHA results by [2], using accelerograms provided in the NGA database [13]. The intensity levels selected to represent the range of seismic intensity at the site is consistent with [3] where eight intensity levels are considered. A total of 20 records ( 2 horizontal components) are chosen for each hazard level.

One major simplifying assumption that was made for the record selection process was the selection of two suites of records. The first low intensity suite was selected based on the disaggregation of the three lowest hazard levels with respect to magnitude, $M$, distance, $r$, and the spectral shape parameter epsilon, $\varepsilon$. The maximum and minimum record properties were taken as the bounds defined within the range of intensities considered forming the low intensity bins (e.g. LA) as shown in Table 3.

\begin{tabular}{|c|c|c|c|c|c|c|c|c|}
\hline Hazard Level & $S_{a}(T=1 s)(g)$ & Bin & $\mathbf{M}_{\min }$ & $\mathbf{M}_{\max }$ & $\mathbf{r}_{\min }(\mathrm{km})$ & $\mathbf{r}_{\max }(\mathrm{km})$ & $\varepsilon_{\min }$ & $\varepsilon_{\max }$ \\
\hline \multicolumn{9}{|c|}{ Low-Intensity Suite } \\
\hline $50 \% \mathrm{PE}$ in $5 \mathrm{yr}$ & 0.1 & LA & 5.9 & 7.1 & 5 & 35 & -0.5 & 1 \\
\hline $20 \% \mathrm{PE}$ in $5 \mathrm{yr}$ & 0.19 & LB & 6.9 & 8.0 & 40 & 80 & -2 & 0.5 \\
\hline $10 \% \mathrm{PE}$ in $5 \mathrm{yr}$ & 0.26 & $\mathrm{LC}^{*}$ & 6.4 & 7.6 & 100 & $\infty$ & 0 & $\infty$ \\
\hline \multicolumn{9}{|c|}{ High-Intensity Suite } \\
\hline $50 \% \mathrm{PE}$ in $50 \mathrm{yr}$ & 0.3 & & & & & & & \\
\hline $20 \% \mathrm{PE}$ in $50 \mathrm{yr}$ & 0.44 & HA & 5.9 & 7.1 & 5 & 35 & 0 & 2 \\
\hline $10 \% \mathrm{PE}$ in $50 \mathrm{yr}$ & 0.55 & & & & & & & \\
\hline $2 \% \mathrm{PE}$ in $50 \mathrm{yr}$ & 0.82 & $\mathrm{HB}$ & 6.9 & 8 & 40 & 80 & 0 & $\infty$ \\
\hline $0.3 \% \mathrm{PE}$ in $50 \mathrm{yr}$ & 1.20 & & & & & & & \\
\hline
\end{tabular}

* Only three records selected from bin $\mathrm{C}$ representing the lowest hazard level within the low intensity suite

Table 3: Hazard disaggregation used for record selection (after [10]). 
Similarly for the higher intensity hazard levels the record properties were combined to form the high intensity suite (refer Table 3). The partitioning of the hazard levels was based on the presence of negative $\varepsilon$ and similar $M$ and $r$ ranges between the first three hazard levels and the remaining higher intensity hazard levels. More information about the nominal disaggregation of the site can be found within [2].

Accelerograms are scaled to the spectral acceleration at a period of 0.8 seconds using the geometric mean of the two orthogonal components. More detailed information regarding the selected records, selection criteria, and scaling approach can be found within [6].

\section{LOSS RESULTS}

\subsection{Initial comparison using baseline parameters}

The structural models representing the input parameters assumed by the parent studies conducted with the component-based (CB) loss model [3] and the storey-based (SB) loss model [5] are compared in order to represent the case of repeating the same loss assessment in order to verify the repeatability. This model assumes a post-yield slope of $4.0 \%, 6.5 \%$ initial stiffness proportional Rayleigh damping (ISRD) at the first and third modes, and the initial stiffness of beam-column elements assumes secant through 0.4 times the yield force. This model is referred to as model D5 (refer Table 5). The expected annual loss results for the baseline comparison are shown in Figure 10 showing a very reasonable agreement to previous studies with the CB model EAL with a deviation of $+2.2 \%(+0.012 \% \mathrm{MDF})$ and the CB model showing a deviation of $-4.6 \%(-0.042 \% \mathrm{MDF})$. This initial comparison illustrates the reliability of the PEER PBEE approach when considering the differences in input motion selection and analysis assumptions.

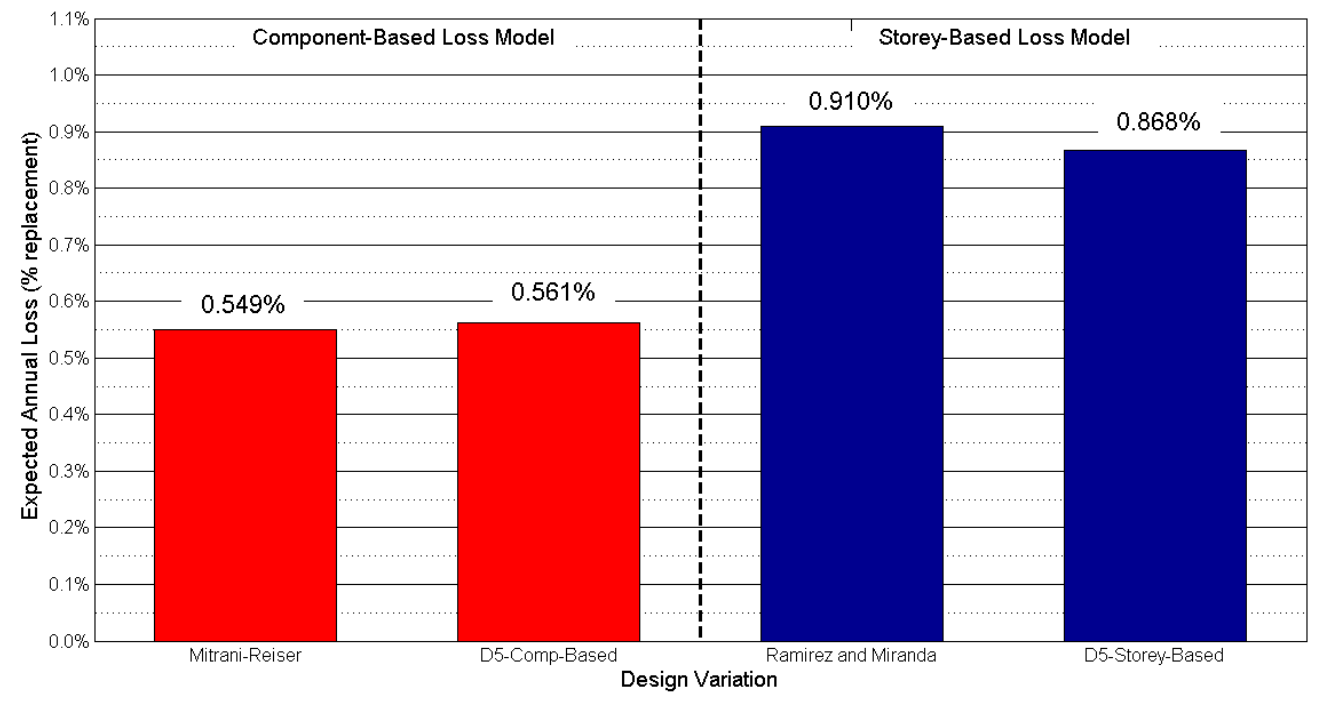

Figure 10: Comparison expected annual loss of baseline models to parent studies.

In order to give the reader a better concept of how deviations in loss estimates may affect decision making, the actual loss values for all loss metrics considered (refer section 3.4) are shown both in MDF (\% replacement cost) and the corresponding dollar values in Table 4. However, it is noted that the remaining comparisons will be discussed in terms of MDF representing the percentage of the replacement cost. The results in Table 4 illustrate that the expected annual loss could produce drastically different risk management decisions based on slight deviations in terms of the magnitude of EAL. For instance, consider that the two values 
from the parent studies $(0.55 \%$ and $0.91 \%)$ are assumed as equally valid results using the replacement cost from the component-based loss model $(\$ 9 \mathrm{M}$ total cost) then the annualized losses for the structure would range from approximately $\$ 49,000$ to $\$ 82,000$.

\begin{tabular}{|c|c|c|c|c|c|c|c|c|}
\hline \multirow[b]{3}{*}{ Loss Metric } & \multicolumn{4}{|c|}{ Component-Based (CB) } & \multicolumn{4}{|c|}{ Storey-Based (SB) } \\
\hline & \multicolumn{2}{|c|}{ [3] (parent) } & \multicolumn{2}{|c|}{ D5 (this study) } & \multicolumn{2}{|c|}{ [5] (parent) } & \multicolumn{2}{|c|}{ D5 (this study) } \\
\hline & $\mathrm{MDF}$ & $\$$ & MDF & $\$ *$ & MDF & $\$^{* *}$ & MDF & $\$$ *** \\
\hline EAL & $0.549 \%$ & 49410 & $0.561 \%$ & 50490 & $0.910 \%$ & 113750 & $0.87 \%$ & 108500 \\
\hline $\mathrm{NPV}_{50}$ & $14.1 \%$ & 1269000 & $14.4 \%$ & 1296000 & $23.4 \%$ & 2925000 & $22.3 \%$ & 2787500 \\
\hline $\mathrm{MDF}_{\mathrm{DBE}}$ & $26.2 \%$ & 2358000 & $22.5 \%$ & 2025000 & $23.5 \%$ & 2937500 & $23.6 \%$ & 2950000 \\
\hline $\mathrm{MDF}_{\mathrm{MCE}}$ & $47.7 \%$ & 4293000 & $42.8 \%$ & 3852000 & $39.0 \%$ & 4875000 & $37.9 \%$ & 4737500 \\
\hline
\end{tabular}

*2007 USD, Total cost $=\$ 9 \mathrm{M}$ (sum of damageable assemblies) ${ }^{* *} 2009$ USD, Total cost $=\$ 12.5 \mathrm{M}$

Table 4: Loss results for baseline comparisons illustrating magnitude of loss metrics.

Conversely, taking the $\mathrm{MDF}_{\mathrm{DBE}}$ values from the two parent studies (26.2\% and $23.5 \%$ ) and again assuming a total cost of $\$ 9 \mathrm{M}$, the loss estimates for a design level event would range from $\$ 2.12 \mathrm{M}$ to $\$ 2.36 \mathrm{M}$ which would give a much larger range in monetary costs when compared to the EAL case yet would, arguably, not drastically affect decisions based on this metric given the differences in probabilistic considerations (annual vs. 10\% in 50y). This point is furthered when considering the implications of estimating total replacement costs.

Now in order to briefly illustrate the difference in the adopted loss models the disaggregation of direct losses conditioned on no collapse for model D5 is plotted versus seismic intensity in Figure 11. The figure displays the direct loss values conditioned on no collapse in terms of structural, non-structural drift sensitive and non-structural acceleration sensitive repair costs (further disaggregation is limited by the performance groups of the storey-based model).

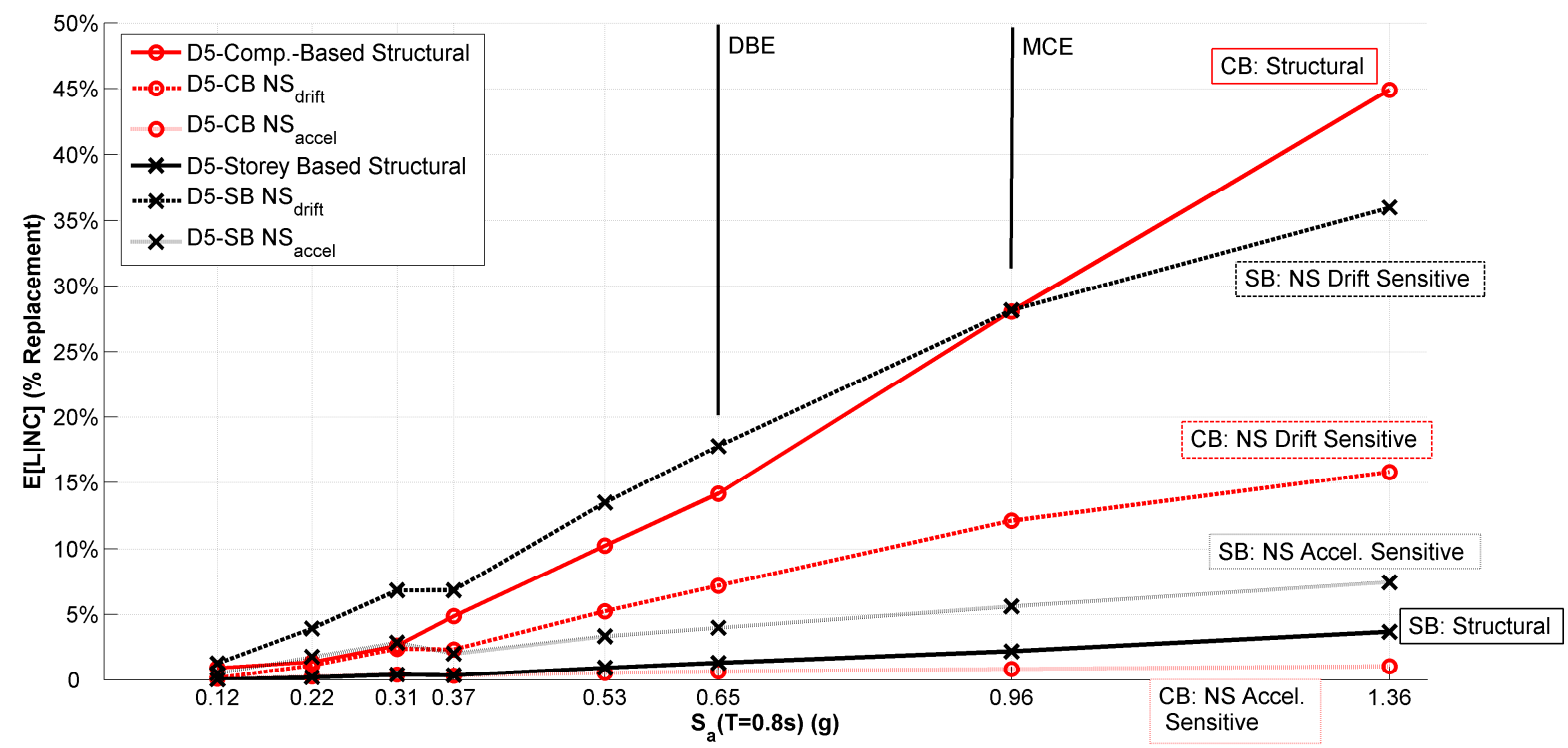

Figure 11: Direct loss disaggregation for baseline model D5.

The main differences in the two loss models are highlighted by simply comparing the governing disaggregated curve from each model; showing structural damage governing the $\mathrm{CB}$ 
model and non-structural drift sensitive damage governing the SB model. This highlights that the CB model assumes the total repair cost of the structure is equal to the replacement cost of each damageable element considered where the repair costs for the replacement of structural elements is weighted most heavily[3,6]. Conversely, the SB model assumes much more repair cost coming from non-structural drift sensitive, $N S_{\text {drift }}$, elements than structural elements since total cost is based on the entire inventory of the structure as shown in Figure 5 and discussed in [5,6]. Additionally, referring to the three lowest intensity levels it is shown that the rate (slope) of the accumulation of losses in $N S_{\text {drift }}$ components is much larger for the SB model and this can be attributed to the use of a partition fragility with a drift of $0.21 \%$ representing the onset of damage (at 50\% confidence) while the CB model assumes that partition damage of $0.39 \%$ which is nearly double this value (refer [3,5]). In lieu of a full crossexamination of the two loss models, these points are deemed necessary to highlight some important differences within them.

\subsection{Results comparing variation of modelling parameters and loss models}

The loss estimates for all model variations are presented in Table 5. The table shows that the mean of the structural model variations considered tend toward the respective parent loss models. The component-based (CB) loss model shows that the EAL estimates are all above the value reported in the parent study $(0.549 \% \quad \mathrm{MDF})$ with a range of $0.561 \%$ to $0.712 \%$ MDF. The storey-based (SB) loss model shows a range that encompasses the parent study value of $0.910 \% \mathrm{MDF}$ with a range of $0.860 \%$ to $0.988 \% \mathrm{MDF}$. Interestingly, both loss models return $\mathrm{MDF}_{\mathrm{DBE}}$ values on the order of $25 \%$, yet the CB loss model estimates the $\mathrm{NPV}_{50}$ to be significantly below $25 \%$ replacement while the SB loss model estimates $\mathrm{NPV}_{50}$ close to the $\mathrm{MDF}_{\mathrm{DBE}}$, noting that this deviation between $\mathrm{NPV}_{50}$ and $\mathrm{MDF}_{\mathrm{DBE}}$ could be an important factor when considering seismic strengthening or other risk mitigation options. This last point serves to illustrate how sensitive the EAL metric could be for decision making and the trends witnessed could vary significantly based on the structure under consideration and the assumed discount rate for the calculation of $\mathrm{NPV}_{50}$ (refer Eq. (2)).

The influence of the individual structural modelling parameters is presented in Table 6. The influence is expressed as simply the mean percent difference (in magnitude) in a particular loss metric estimation between parameter to another. For example the initial stiffness comparison shows the percent difference between the mean values of structural models D5, D6, D7, and D8 to structural models D1, D2, D3, and D4. The assumption of initial elastic damping is clearly shown to be the most influential with differences on the order of $13 \%, 8 \%$, and $6 \%$ for $\mathrm{EAL}, \mathrm{MDF}_{\mathrm{DBE}}$, and $\mathrm{MDF}_{\mathrm{MCE}}$ respectively. Interestingly, the initial effective stiffness shows a much more significant impact on the CB loss model which is directly accounted for by two factors: the structural damage is estimated by a damage index requiring an estimation of the recoverable curvature (a function of the individual stiffness of the member) and the heavy weighting given to structural repairs (refer Figure 11). Conversely, the SB loss model is not affected significantly by the initial stiffness assumption where, in this case, the global stiffness (fundamental period) of the structure was not witnessed to change drastically (refer Section 4.3) which highlights the sensitivity to this assumption when utilizing a damage index based on recoverable curvature. The hysteretic and post-yielding assumptions were not shown to be significant which gives further reliability in performing loss assessments using the PEER PBEE approach given the numerous variations and decisions that can be associated with structural element calibration. 


\begin{tabular}{|c|c|c|c|c|c|c|c|}
\hline MODEL & $\begin{array}{c}\text { Hysteresis }^{*} \\
\text { (post-yield factor) }\end{array}$ & $\begin{array}{c}\text { Initial } \\
\text { Effective } \\
\text { Stiffness } \\
\text { EI }_{\text {0,eff }}^{* *}\end{array}$ & $\begin{array}{c}\text { Elastic } \\
\text { Damping } \\
\xi_{\text {el }}^{* * *}\end{array}$ & $\begin{array}{c}\text { Expected } \\
\text { Annual } \\
\text { Loss } \\
\text { EAL }\end{array}$ & $\begin{array}{c}\text { Net } \\
\text { Present } \\
\text { Value } \\
\text { NPV }_{\mathbf{5 0}}\end{array}$ & $\begin{array}{c}\text { Design } \\
\text { Intensity } \\
\text { Scenario } \\
\text { MDF }_{\text {DBE }}\end{array}$ & $\begin{array}{l}\text { Maximum } \\
\text { Credible } \\
\text { Scenario } \\
\text { MDF }_{\text {MCE }}\end{array}$ \\
\hline \multicolumn{4}{|c|}{ Component-Based Loss Model [3] } & $0.549 \%$ & $14.1 \%$ & $26.2 \%$ & $47.7 \%$ \\
\hline \multicolumn{4}{|c|}{ Mean-CB (this study) } & $0.641 \%$ & $16.5 \%$ & $24.4 \%$ & $45.4 \%$ \\
\hline D1-CB & $\mathrm{DBC}(\mathrm{r}=0.04)$ & $\mathrm{M}_{\mathrm{n}} / \varphi_{\mathrm{y}}$ & $6.5 \%$ & $0.643 \%$ & $16.3 \%$ & $23.7 \%$ & $43.1 \%$ \\
\hline D2-CB & $\mathrm{DBC}(\mathrm{r}=0.04)$ & $\mathrm{M}_{\mathrm{n}} / \varphi_{\mathrm{y}}$ & $5.0 \%$ & $0.703 \%$ & $18.1 \%$ & $25.6 \%$ & $45.9 \%$ \\
\hline D3-CB & $\mathrm{DB}(\mathrm{r}=0.01)$ & $\mathrm{M}_{\mathrm{n}} / \varphi_{\mathrm{y}}$ & $6.5 \%$ & $0.635 \%$ & $16.3 \%$ & $24.3 \%$ & $45.1 \%$ \\
\hline D4-CB & $\mathrm{DB}(\mathrm{r}=0.01)$ & $\mathrm{M}_{\mathrm{n}} / \varphi_{\mathrm{y}}$ & $5.0 \%$ & $0.712 \%$ & $18.3 \%$ & $26.0 \%$ & $48.2 \%$ \\
\hline D5-CB & $\mathrm{DBC}(\mathrm{r}=0.04)$ & $0.35 \mathrm{EI}_{\mathrm{g}}$ & $6.5 \%$ & $0.561 \%$ & $14.4 \%$ & $22.5 \%$ & $42.8 \%$ \\
\hline D6-CB & $\mathrm{DBC}(\mathrm{r}=0.04)$ & $0.35 \mathrm{EI}_{\mathrm{g}}$ & $5.0 \%$ & $0.646 \%$ & $16.6 \%$ & $24.5 \%$ & $45.6 \%$ \\
\hline D7-CB & $\mathrm{DB}(\mathrm{r}=0.01)$ & $0.35 \mathrm{EI}_{\mathrm{g}}$ & $6.5 \%$ & $0.571 \%$ & $14.7 \%$ & $23.2 \%$ & $44.7 \%$ \\
\hline D8-CB & $\mathrm{DB}(\mathrm{r}=0.01)$ & $0.35 \mathrm{EI}_{\mathrm{g}}$ & $5.0 \%$ & $0.656 \%$ & $16.9 \%$ & $25.2 \%$ & $47.6 \%$ \\
\hline \multicolumn{4}{|c|}{ Storey-Based Loss Model [5] } & $0.910 \%$ & $23.4 \%$ & $23.5 \%$ & $39.0 \%$ \\
\hline \multicolumn{4}{|c|}{ Mean-SB (this study) } & $0.927 \%$ & $23.9 \%$ & $24.6 \%$ & $39.1 \%$ \\
\hline D1-SB & $\mathrm{DBC}(\mathrm{r}=0.04)$ & $\mathrm{M}_{\mathrm{n}} / \varphi_{\mathrm{y}}$ & $6.5 \%$ & $0.860 \%$ & $22.2 \%$ & $23.9 \%$ & $38.5 \%$ \\
\hline D2-SB & $\mathrm{DBC}(\mathrm{r}=0.04)$ & $\mathrm{M}_{\mathrm{n}} / \varphi_{\mathrm{y}}$ & $5.0 \%$ & $0.988 \%$ & $25.4 \%$ & $25.8 \%$ & $40.4 \%$ \\
\hline D3-SB & $\mathrm{DB}(\mathrm{r}=0.01)$ & $\mathrm{M}_{\mathrm{n}} / \varphi_{\mathrm{y}}$ & $6.5 \%$ & $0.877 \%$ & $22.6 \%$ & $23.5 \%$ & $38.2 \%$ \\
\hline D4-SB & $\mathrm{DB}(\mathrm{r}=0.01)$ & $\mathrm{M}_{\mathrm{n}} / \varphi_{\mathrm{y}}$ & $5.0 \%$ & $0.983 \%$ & $25.3 \%$ & $25.4 \%$ & $40.4 \%$ \\
\hline D5-SB & $\mathrm{DBC}(\mathrm{r}=0.04)$ & $0.35 \mathrm{EI}_{\mathrm{g}}$ & $6.5 \%$ & $0.868 \%$ & $22.3 \%$ & $23.6 \%$ & $37.9 \%$ \\
\hline D6-SB & $\mathrm{DBC}(\mathrm{r}=0.04)$ & $0.35 \mathrm{EI}_{\mathrm{g}}$ & $5.0 \%$ & $0.985 \%$ & $25.4 \%$ & $25.4 \%$ & $39.6 \%$ \\
\hline D7-SB & $\mathrm{DB}(\mathrm{r}=0.01)$ & $0.35 \mathrm{EI}_{\mathrm{g}}$ & $6.5 \%$ & $0.865 \%$ & $22.3 \%$ & $23.5 \%$ & $37.8 \%$ \\
\hline D8-SB & $\mathrm{DB}(\mathrm{r}=0.01)$ & $0.35 \mathrm{EI}_{\mathrm{g}}$ & $5.0 \%$ & $0.987 \%$ & $25.4 \%$ & $25.3 \%$ & $39.8 \%$ \\
\hline
\end{tabular}

*DB-Ductility Based, DBC-Ductility Based Cyclic -All values reported as a percentage of replacement cost

${ }^{* *} \mathrm{M}_{\mathrm{n}} / \varphi_{\mathrm{y}}$ : secant stiffness to nominal yield, $0.35 \mathrm{EI}_{\text {gross }}$ : corresponds to secant through $40 \%$ of yield after [1]

**** Initial stiffness proportional Rayleigh damping ratio (\% critical) applied at the first and third fundamental modes

Table 5: Loss results for nominal model variations in comparison with parent studies.

\begin{tabular}{|c|c|c|c|c|c|c|}
\hline & & & & $\begin{array}{c}\text { Expected } \\
\text { Annual } \\
\text { Loss } \\
\end{array}$ & $\begin{array}{c}\text { Design } \\
\text { Intensity } \\
\text { Scenario } \\
\end{array}$ & $\begin{array}{c}\text { Maximum } \\
\text { Credible } \\
\text { Scenario } \\
\end{array}$ \\
\hline \multicolumn{2}{|c|}{ Parameter } & Description & Loss Model & EAL & MDF $_{\text {DBE }}$ & MDF $_{\text {MCE }}$ \\
\hline \multirow{2}{*}{$\begin{array}{c}\text { Elastic } \\
\text { Damping }\end{array}$} & \multirow{2}{*}{$\xi_{\text {elastic }}^{*}$} & \multirow{2}{*}{$6.5 \%$ to $5 \%$} & Component-Based [3] & $+12.7 \%$ & $+8.2 \%$ & $+6.6 \%$ \\
\hline & & & Storey-Based [5] & $+13.6 \%$ & $+7.9 \%$ & $+5.2 \%$ \\
\hline \multirow{2}{*}{$\begin{array}{c}\text { Initial } \\
\text { Effective } \\
\text { Stiffness } \\
\end{array}$} & \multirow{2}{*}{$\mathrm{EI}_{0, \mathrm{eff}}$} & \multirow{2}{*}{$\begin{array}{c}0.35 \mathrm{EI}_{\text {gross }} \text { to } \\
\mathrm{M}_{\mathrm{n}} / \varphi_{\mathrm{y}}\end{array}$} & Component-Based [3] & $+10.7 \%$ & $+4.3 \%$ & $+0.9 \%$ \\
\hline & & & Storey-Based [5] & $+0.1 \%$ & $+0.9 \%$ & $+1.5 \%$ \\
\hline \multirow{2}{*}{$\begin{array}{c}\text { Hysteresis } \\
\text { and Post-Yield } \\
\text { Factor }\end{array}$} & \multirow[b]{2}{*}{$\mathrm{r}$} & \multirow{2}{*}{0.04 to 0.01} & Component-Based [3] & $+0.1 \%$ & $+2.4 \%$ & $+4.6 \%$ \\
\hline & & & Storey-Based [5] & $+0.3 \%$ & $-1.0 \%$ & $-0.1 \%$ \\
\hline
\end{tabular}

*Initial stiffness proportional Rayleigh damping at the first and third modes

*** post-yield stiffness factor -Values expressed as \% difference

Table 6: Comparison of mean magnitudes of deviations between modelling parameters. 


\section{CONCLUSIONS}

- The recreation of the PEER PBEE methodology for a four-storey case study building returned similar results to parent studies highlighting the reliability in the method despite differences in analysis assumptions in order to conduct the loss assessment.

- The impact of structural modelling parameters that could represent a small set of analyst decisions showed reasonable reliability with respect to the overall deviations from the previous values reported in previous studies

- The treatment of elastic damping was shown to be the most significant of the parameters addressed which suggests that a probabilistic consideration of this parameter may be necessary in an optimized case. Conversely, in a more practical case where a deterministic value would be utilized the analyst should be aware of the implications of assigning elastic damping by rule of thumb or intuition.

- The two loss models considered varied considerably in formulation and philosophy. The component-based model provides a greater sense of accuracy as the actual take-off quantities of damageable components are considered for damage analysis rather than typical expected contents as in the storey-based model. Conversely, the storey-based model considers the entire value of the building which is more conceptually sound than the component-based model that only attributes the entire cost to the full replacement cost of components assigned fragilities which leads to a much higher weighting of structural damage. Further loss model developments should aim to combine both of the beneficial aspects of the two models, yet the feasibility of this within a real assessment will be governed by available information and time constraints where the loss model approach will rely heavily on the decisions of the analyst.

- The expected annual loss (EAL) was shown to be the most sensitive loss metric to variations in the loss model adopted, where the simulations of different modelling parameters tended toward the respective parent study. The importance of the deviations of EAL is founded in the implications of its use as a decision variable (insurance, annual improvements) highlights the need for careful formulation of the damage analysis and repair cost stages of the PEER PBEE approach as well as continued research into the development of component fragilities and repair cost functions.

\section{ACKNOWLEDGEMENT}

This research is developed as part of research line AT1-2 of the 2010-2013 RELUIS project. As such, the authors gratefully acknowledge the financial support of the RELUIS consortium (www.reluis.it) for this research.

\section{REFERENCES}

[1] C.B. Haselton, G.G. Deierlein, Assessing seismic collapse safety of modern reinforced concrete moment frame buildings. John A. Blume Earthquake Engineering Center, Technical Report No. 156, Stanford University, 2007.

[2] C. Goulet, C. Haselton, J. Mitrani-Reiser, J.P. Stewart, E. Taciroglu, G. Deierlein, Evaluation of the seismic performance of a code-conforming reinforced concrete frame building - Part 1: Ground motion selection and structural collapse simulation. Proceed- 
ings of $8^{\text {th }}$ National Conference on Earthquake Engineering, San Francisco, California, 2006.

[3] J. Mitrani-Reiser, J.L. Beck, An ounce of prevention: Probabilistic loss estimation for performance-based earthquake engineering. PhD Dissertation, California Institute of Technology (Caltech), Pasadena, California, 2007.

[4] K.A. Porter, An Overview of PEER's Performance-Based Earthquake Engineering Methodology. Proceedings of Ninth International Conference on Applications of Statistics and Probability in Engineering, San Francisco, California, 2003.

[5] C.M. Ramirez, E. Miranda, Building specific loss estimation methods \& tools for simplified performance-based earthquake engineering. John A. Blume Earthquake Engineering Center, Technical Report No. 171, Stanford University, 2009.

[6] D.P. Welch, T.J. Sullivan, G.M. Calvi, Developing Direct Displacement-Based Design and Assessment Procedures for Performance-Based Earthquake Engineering. ROSE Report 2012/03, IUSS Press, Pavia, Italy, 2012.

[7] Applied Technology Council, Guidelines for Seismic Performance Assessment of Buildings. ATC-58: 75\% Complete Draft, Redwood City, California, 2011.

[8] A.B. Liel, G.G. Deierlein, Assessing the Collapse Risk of California's Existing Reinforced Concrete Frame Structures: Metrics for Seismic Safety Decisions. John A. Blume Earthquake Engineering Center, Technical Report No. 166, Stanford University, 2008.

[9] A.J. Carr, RUAUMOKO-Users Manual, Theory, and Appendices. Vol. 2, User manual for the 2-Dimensional version, University of Canterbury, Christchurch, New Zealand, 2007.

[10] C.B. Haselton, C.A. Goulet, J.L. Beck, G.G. Deierlein, K.A. Porter, J.P. Stewart, E. Taciroglu, An assessment to benchmark the seismic performance of a code-conforming reinforced concrete moment-frame building. Pacific Earthquake Engineering Research Center (PEER), Report No. PEER 2007/12, University of California, Berkeley, 2007.

[11] L.A. Montejo, M.J. Kowalsky, CUMBIA: Set of codes for the analysis of reinforced concrete members. Technical report No. IS-07-01, Prepared for Alaska Department of Transportation, Constructed Facilities Laboratory, North Carolina State University, Raleigh, North Carolina, 2007.

[12] M.J.N. Priestley, G.M. Calvi, M.J. Kowalsky, Displacement-Based Seismic Design of Structures, IUSS Press, Pavia, Italy, 2007.

[13] PEER, Pacific Earthquake Engineering Research Center: Strong Motion Database, University of California, Berkeley, http://peer.berkeley.edu, 2011.

[14] D.P. Welch, T.J. Sullivan, G.M. Calvi, Towards a Direct Displacement-Based Loss Assessment Methodology for RC Frame Buildings. Proceedings of the $15^{\text {th }}$ World Conference on Earthquake Engineering, Lisbon, Portugal, September 24-28, 2012. 